\title{
Cellular studies of an aminoglycoside potentiator reveal a new inhibitor of aminoglycoside resistance
}

\author{
Jinming Guan, ${ }^{[\mathrm{a}]}$ Kenward Vong, ${ }^{[\mathrm{a}]}$ Kathleen Wee, ${ }^{[\mathrm{b}]}$ Johans Fakhoury, ${ }^{\mathrm{a}]}$ Edie Dullaghan, ${ }^{[\mathrm{b}]}$
} Karine Auclair ${ }^{[\mathrm{a}]}$

\begin{abstract}
Aminoglycosides are a group of broad-spectrum antibiotics that have been used in the clinic for almost a century. The rapid spread of bacterial genes coding for aminoglycoside-modifying enzymes has however dramatically decreased the utility of aminoglycosides. We have previously reported several aminoglycoside potentiators which work by inhibiting aminoglycoside $N$ - 6 'acetyltransferase, one of the most common determinants of aminoglycoside resistance. Among those, pro-drugs that combine the structure of an aminoglycoside with that of pantothenate into one molecule are especially promising. We report here, a series of cellular studies to further investigate the activity and mechanism of action of these prodrugs. Our results reveal a new aminoglycoside resistance inhibitor, and the possibility that these prodrugs are transformed into more than one inhibitor in bacteria. We also report that the onset of the potentiators is rapid. Their low cell cytotoxicity, good stability and potentiation of various aminoglycosides, against both Gram-positive and Gram-negative bacteria, make them interesting compounds for the development of new drugs.
\end{abstract}

\section{Introduction}

Aminoglycosides are a group of highly potent, broad-spectrum antibiotics currently used to treat serious infections in a hospital setting. ${ }^{[1]-[2]}$ Their lethal effect on bacteria is mostly attributed to their binding to bacterial ribosomes, and causing infidelity during protein synthesis. ${ }^{[1]-[2]}$ As with all antibiotics, resistance to aminoglycosides has spread widely. ${ }^{[3]}$ The most common mechanism of aminoglycoside resistance involves the production of aminoglycoside-modifying enzymes such as aminoglycoside $N$-acetyltransferases (AACs), aminoglycoside $O$-phosphotransferases (APHs) and aminoglycoside $O$-nucleotidyltransferases (ANTs). ${ }^{[4]}$ The AAC family of enzymes is the largest one of the three, with over fifty AACs identified in various organisms. ${ }^{[3],[5]}$ They use acetyl-coenzyme A ( $\mathrm{AcCoA})$ to acetylate free amines at the 1, 3, 2' or 6' position of aminoglycosides (Figure 1), and are thus classified as AAC(1), AAC(3), AAC(2') or AAC(6'), respectively. ${ }^{[1]}$ AACs are further divided between subtypes I or II, based on the resistance profile that they cause (i.e. substrate scope), and a lower case letter at the end of the name defines the specific isoform. ${ }^{[1]} \mathrm{AAC}\left(6^{\prime}\right)$ is by far the most prevalent in clinical strains. ${ }^{[3]}$ Interestingly, some bacteria, such as the important human pathogen Enterococcus faecium, harbor an ACC(6')coding gene on a chromosome, which renders them intrinsically resistant to aminoglycosides. ${ }^{[6]}$

\footnotetext{
[a] J. Guan, Dr. K. Vong, Dr. J. Fakhoury, Prof. K. Auclair Department of Chemistry McGill University 801 Sherbrooke Street West, Montreal, Quebec, Canada, H3A 0B8 E-mail: karine.auclair@mcgill.ca

[b] Dr. K. Wee, Dr. E. Dullaghan, Target Validation Division The Centre for Drug Research and Development 2405 Westbrook Mall, $4^{\text {th }}$ Floor, Vancouver, British Columbia, Canada, V6T 1 Z3 


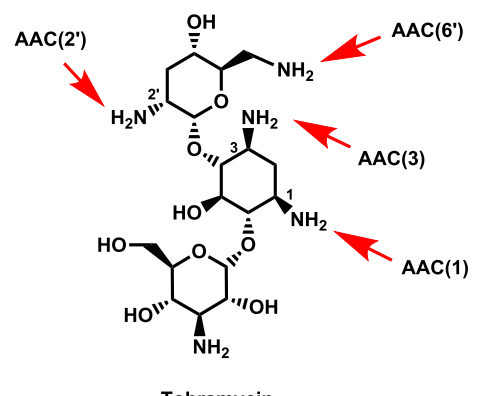

Figure 1. Susceptible sites for modifications by different AACs, shown using tobramycin as an example. ${ }^{[1]}$

To overcome aminoglycoside resistance, two strategies have been investigated by different labs: 1) modifying aminoglycosides to make them refractory to transformations by resistance-causing enzymes while maintaining their potency; and 2) blocking aminoglycoside resistance. ${ }^{[5]}$ Our lab has had interest in the latter, ${ }^{[7]-[15]}$ with neamine derivatives 1a-e being promising inhibitors of the Enterococci isoform AAC(6')-li (Figure 2). ${ }^{[7],[15]}$ While derivatives of other aminoglycosides have also been reported, they show slightly lower activity (e.g. the $\mathrm{K}_{\mathrm{i}}$ of the neamine derivative 1a is $76 \mathrm{nM}$, compared to $119 \mathrm{nM}$ and $111 \mathrm{nM}$ for the corresponding kanamycin $\mathrm{A}$ and ribostamycin derivatives respectively). ${ }^{[7]}$ Unfortunately, 1a-e cannot penetrate bacterial cells and have no activity in cellulo. To address the permeability issue, a series of prodrugs, P-1a-e, designed to be bioactivated into 1a-e by enzymes of the bacterial CoA biosynthetic pathway, were next reported. ${ }^{[15]} \mathbf{P}-\mathbf{1 a}-\mathbf{e}$ have no antibacterial activity of their own, do not inhibit $A C C\left(6^{\prime}\right)$-li significantly, yet, except for P-1a, potentiate the activity of kanamycin A against aminoglycoside-resistant $E$. faecium (harboring a chromosomally-encoded aac $\left(6^{\prime}\right)$ ). ${ }^{[15]}$ The difference between P-1a and P-1b-e was rationalized via in vitro studies, which showed that compounds $\mathbf{P}-\mathbf{1} \mathbf{b}-\mathbf{e}$ were transformed into inhibitors $\mathbf{1 b}$-e by three of the E. coli CoA biosynthetic enzymes (Figure 2): pantothenate kinase (PanK, EC 2.7.1.33), phosphopantetheine adenylyltransferase (PPAT, EC 2.7.7.3) and dephospho-CoA kinase (DPCK, EC 2.7.1.24), whereas P1a was not converted to inhibitor 1a. Since 1a was not produced, AAC(6')-li may not be inhibited, which may explain the absence of kanamycin A potentiation by $\mathbf{P}-\mathbf{1 a}$.

Compounds P-1a-e are not inhibiting bacterial growth on their own, consequently exerting much less pressure on bacterial growth, and since the unnatural part of these molecules (relative to pantothenate) is expected to lie outside the active site of the three bioactivating enzymes, ${ }^{[16]-[18]}$ resistance development for these compounds is expected to emerge more slowly. This advantage of compounds P-1a-e, and the interesting activity of $\mathbf{P}-\mathbf{1} \mathbf{b}-\mathbf{e}$ motivated us to pursue in cellulo and stability studies of $\mathbf{P}-1 \mathbf{a}-\mathbf{e}$. 
<smiles>CC(C)(C)[P+](=O)[O-]</smiles>

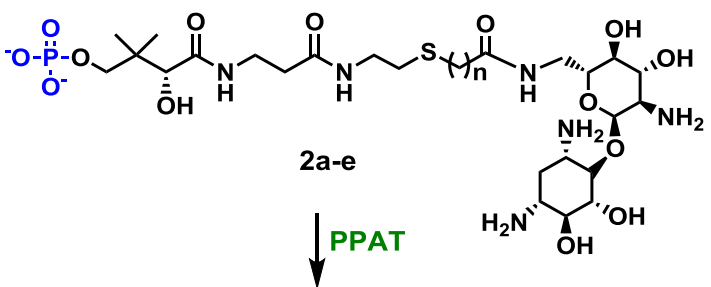

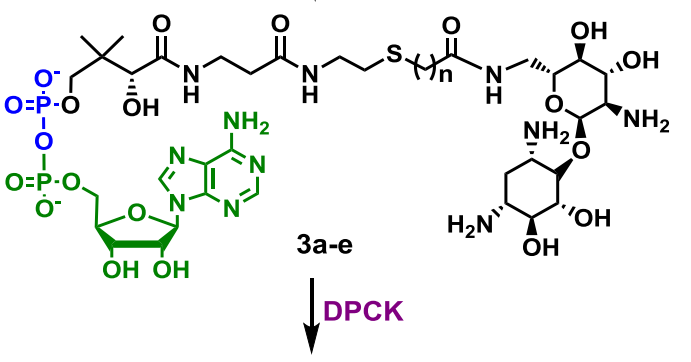

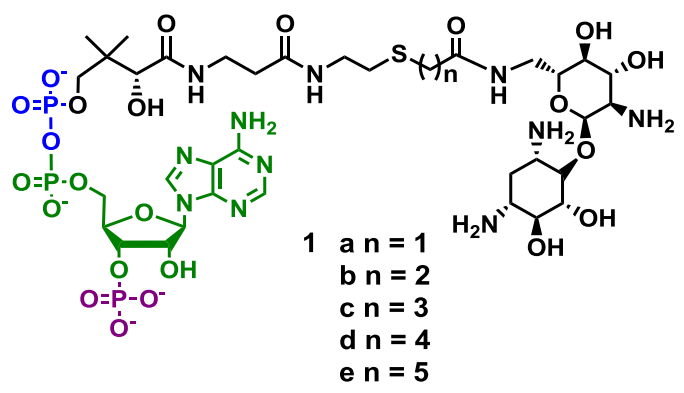

Figure 2. Proposed transformation of P-1a-e to the corresponding AAC(6')-li inhibitors 1a-e by enzymes of the CoA biosynthetic pathway.

\section{Results and Discussion}

\section{P-1a-e potentiate the antibacterial effect of different aminoglycosides}

Compounds P-1b-e were reported to potentiate the antibacterial activity of kanamycin A, a 4,6-linked aminoglycoside, against the intrinsically resistant E. faecium ${ }^{[15]}$ To investigate the scope of potentiation by $\mathbf{P}-\mathbf{1 a - e}$, we tested them in combination with two additional aminoglycosides, tobramycin and ribostamycin, which were selected not only because they are 4,5-linked antibiotics but also because E. faecium ATCC 19434 is more resistant to these aminoglycosides (MIC values $>200 \mu \mathrm{g} / \mathrm{mL}$, see Table S1) than to kanamycin A (128 $\mu \mathrm{g} / \mathrm{mL})$. While P-1a did not potentiate the activity of ribostamycin or tobramycin by much, P-1b-e greatly reduced the MIC of both aminoglycosides (Figure $3 \mathrm{~A}$ ). This trend is consistent with that reported for kanamycin A with $\mathbf{P}-\mathbf{1 a}-\mathbf{e},{ }^{[15]}$ and demonstrates that $\mathbf{P}-\mathbf{1 b}-\mathbf{e}$ can potentiate the activity of various aminoglycosides. Since compounds $\mathbf{P}-\mathbf{1} \mathbf{b}-\mathbf{e}$ show a similar potentiating effect, the tobramycin-P-1b combination shows the best antibacterial activity, and the inhibitors $\mathbf{1 b}-\mathbf{c}$ are reported to be more potent than $\mathbf{1} \mathbf{d}-\mathbf{e},,^{[7],[15]}$ all subsequent experiments were performed with P-1b and/or P-1c.

Dose-response relationships were next examined. As shown in Figure 3B-C, the higher the concentration of $\mathbf{P}-\mathbf{1 b}$ or $\mathbf{P}-\mathbf{1 c}$ used, the less aminoglycoside is required to inhibit the growth of E. faecium ATCC 19434; and the higher the concentration of aminoglycoside, the less $\mathbf{P}-\mathbf{1 b}$ or $\mathbf{P}-\mathbf{1 c}$ is required to achieve the same growth inhibitory effect. This phenotype is within expectation since more $\mathbf{P}-\mathbf{1 b}$ or $\mathbf{P}-\mathbf{1 c}$ should lead to more $\mathrm{AAC}\left(6^{\prime}\right)$-li inhibition in $E$. faecium, leaving the bacteria more sensitive to the aminoglycoside and consequently requiring less aminoglycoside. Furthermore, Figure $3 B-C$ reveal that at 
concentrations of tobramycin $\leq 15 \mu \mathrm{g} / \mathrm{mL}$, which is a pharmaceutically-relevant concentration, ${ }^{[19]-[21]}$ the minimal concentration of $\mathbf{P}-\mathbf{1} \mathbf{b}$ required to significantly inhibit the growth of $E$. faecium is $192 \mu \mathrm{g} / \mathrm{mL}$.

It is worth noting that while P-1a did not potentiate the activity of kanamycin A or tobramycin, it does lower the MIC of ribostamycin towards $E$. faecium by ca. $100 \mu \mathrm{g} / \mathrm{mL}$ (Figure $3 \mathrm{~A}$, right panel). This cannot be explained if compound $1 \mathrm{a}$ is the active AAC(6')-li inhibitor since a previous in vitro study has shown that $\mathbf{P}-\mathbf{1 a}$ is only transformed into $\mathbf{2 a}$ (5\% yield) and $\mathbf{3 a}$ (25\% yield) by the CoA biosynthetic enzymes (Figure 2 ), with $70 \%$ of unmodified P-1a, and no 1a observed. ${ }^{[15]}$ One possible explanation for this unexpected result may be a difference in enzyme activity between in vitro and in cellulo conditions, alternatively a difference in activity between the $E$. coli CoA biosynthetic enzymes (used for the in vitro studies) ${ }^{[15]}$ and the $E$. faecium enzymes (used for the in cellulo studies). The sequence identity of PanK, PPAT and DPCK between these two bacteria is $44 \%, 46 \%$ and $36 \%$, respectively. To investigate this, we next looked at the metabolism of P-1b in E. faecium cells.
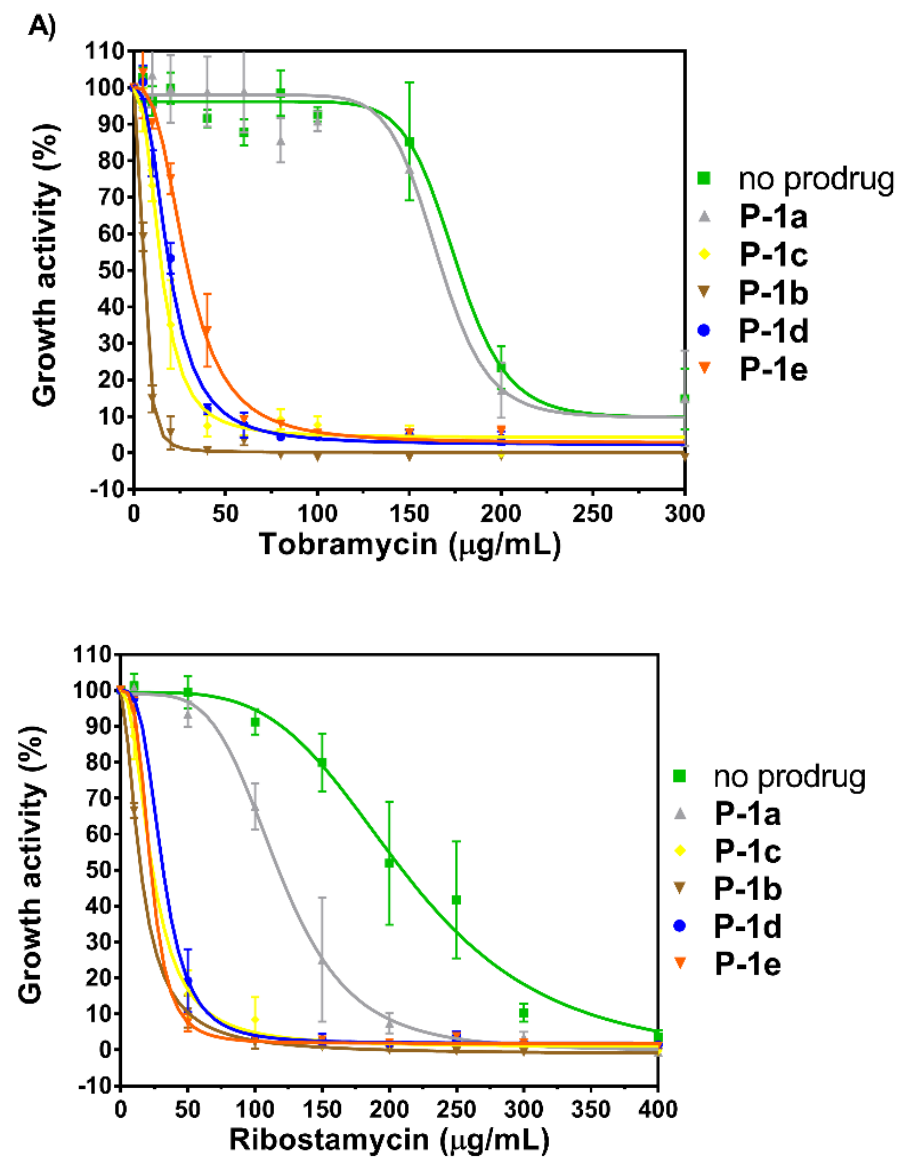
B)

P-1b

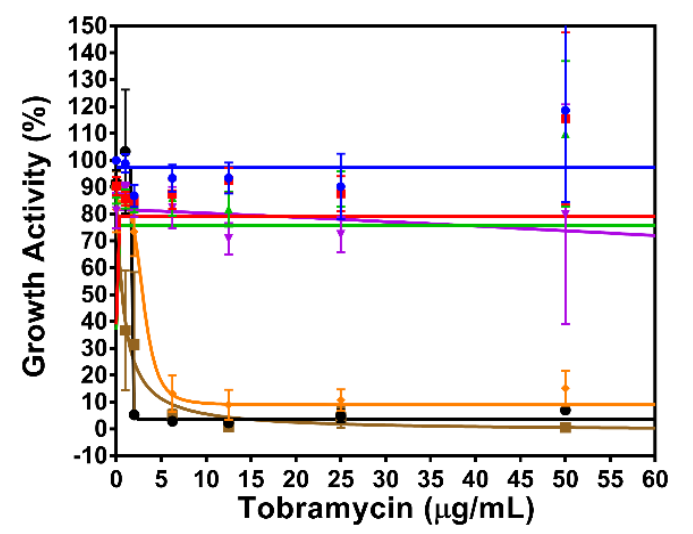

P-1b conc.

$(\mu \mathrm{g} / \mathrm{mL})$

$\rightarrow 0$

$-48$

- 96

- 144

+ 192

- 256

- 384

C)

P-1c

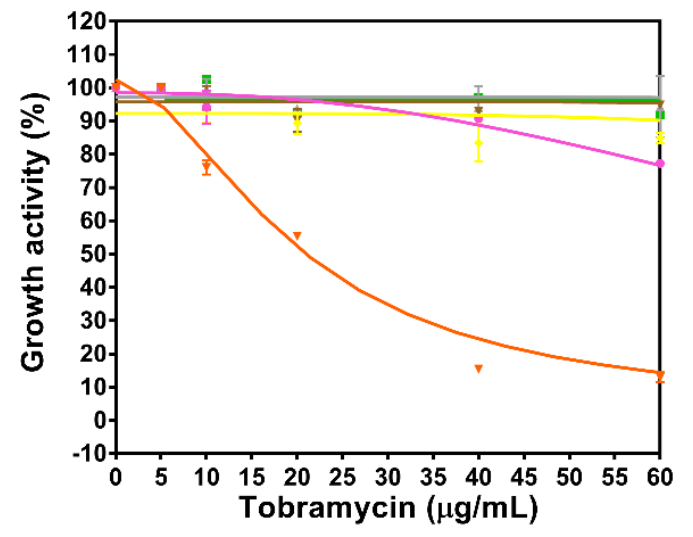

P-1c conc.

$(\mu \mathrm{g} / \mathrm{mL})$

$=0$

$+32$

- 64

-128
$-\quad 256$

$-256$

- 512

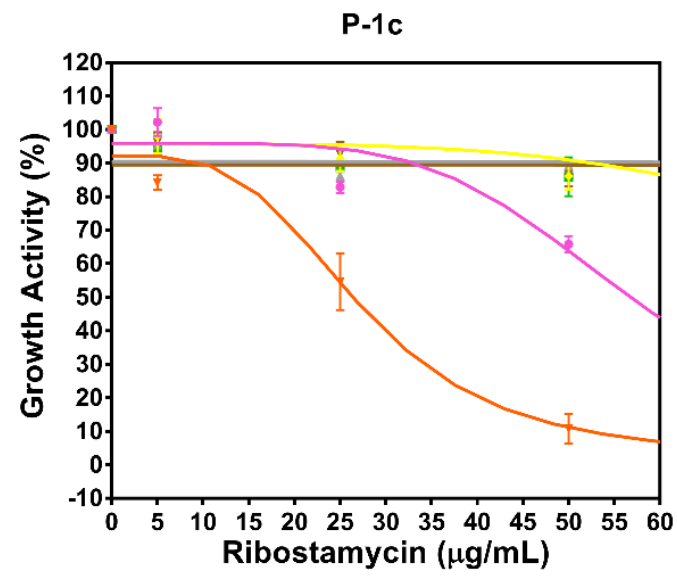

P-1c conc.

$(\mu \mathrm{g} / \mathrm{mL})$

$=0$

$-32$

- 64

-128
+-256

$-256$

$+512$

Figure 3. MIC plots reporting the antibacterial activity of different aminoglycosides (x-axis label) towards E. faecium ATCC 19434, in the presence or absence of potentiator, A) at $512 \mu \mathrm{g} / \mathrm{mL}$ of compounds P-1a-e; B) at different concentrations of P-1b, or C) at different concentrations of P-1c.

Time-kill studies with P-1b

To choose the time window for in cellulo investigations, time-kill studies were performed with an initial E. faecium culture of $10^{5} \mathrm{CFU} / \mathrm{mL}$. As shown in Figure 4, when no tobramycin nor $\mathbf{P}-\mathbf{1 b}$ are added to the growth medium, or when only $\mathbf{P}-\mathbf{1 b}$ is 
added, E. faecium replicates exponentially and reaches $10^{6} \mathrm{CFU} / \mathrm{mL}$ within $\sim 2 \mathrm{~h}$. In the presence of $100 \mu \mathrm{g} / \mathrm{mL}$ tobramycin, E. faecium grows slower, taking 4-6 h to reach the same cell density. In contrast, when both $384 \mu \mathrm{g} / \mathrm{mL}$ of $\mathbf{P}-\mathbf{1 b}$ and 25 $\mu \mathrm{g} / \mathrm{mL}$ of tobramycin (a combination known to lead to $100 \%$ growth inhibition) are added to the growth medium, E. faecium remains in static growth for $\sim 8 \mathrm{~h}$. Finally, when the concentration of tobramycin in the medium is raised to $50 \mu \mathrm{g} / \mathrm{mL}$ or $\mathrm{more}$ (and $\mathbf{P}-\mathbf{1 b}$ is kept at $384 \mu \mathrm{g} / \mathrm{mL}$ ), the number of $E$. faecium CFU/mL decreases slowly over the first $8 \mathrm{~h}$, and takes more than $16 \mathrm{~h}$ to recover (based on the MIC studies). Because the drop in bacterial concentration is only ca. 20-fold, this combination of tobramycin and $\mathbf{P - 1} \mathbf{b}$ is considered bacteriostatic (drop less than 1000-fold), not bactericidal (drop more than 1000fold). ${ }^{[22]}$ Interestingly, under these conditions, the cell concentration of $E$. faecium decreases continuously over $8 \mathrm{~h}$, with a decrease rate proportional to the tobramycin concentration, suggesting that the $\mathbf{P}-\mathbf{1} \mathbf{b}$-tobramycin combination is concentration-dependent, as reported for aminoglycosides when used alone. ${ }^{[23]}$ More importantly, when comparing the timekill curves for tobramycin with or without $\mathbf{P}-\mathbf{1 b}$, it is interesting to note that at time $4 \mathrm{~h}$, the $\mathrm{CFU} / \mathrm{mL}$ differ by almost 2 orders of magnitude, indicating that $\mathbf{P}-\mathbf{1 b}$ takes effect well before four hours. Therefore, the $0-4 \mathrm{~h}$ is a critical time window to study the in cellulo transformation of $\mathbf{P}-\mathbf{1} \mathbf{b}$.

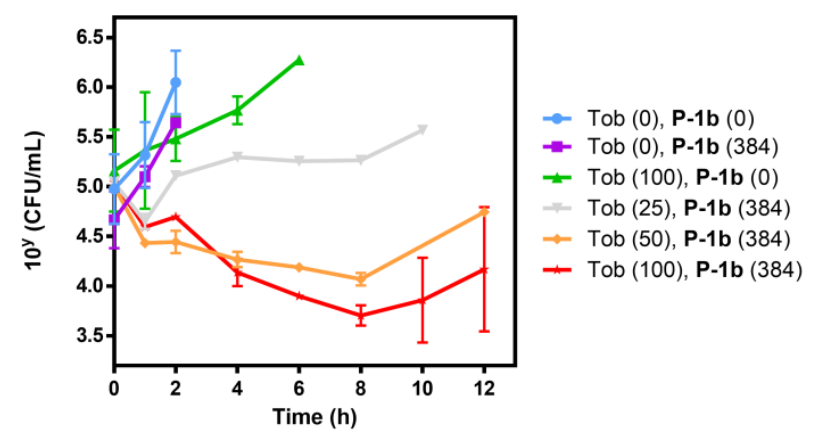

Figure 4. Time-kill curves of E. faecium ATCC 19434 in the presence of different concentrations of P-1b and tobramycin. Tob: tobramycin. The values in brackets in the legend are concentrations, in $\mu \mathrm{g} / \mathrm{mL}$.

\section{Bioactivation of P-1b in E. faecium ATCC 19434}

To investigate the bioactivation of $\mathbf{P}-\mathbf{1 b}$ in $E$. faecium, $17 \times 10^{9}$ colonies of $E$. faecium were collected every hour after the addition of $\mathbf{P}-\mathbf{1 b}(384 \mu \mathrm{g} / \mathrm{mL})$ into the growth medium. The cells were washed, lysed and the metabolites were extracted at $0^{\circ} \mathrm{C}$, before LCMS analysis to quantify $\mathbf{P}-\mathbf{1 b}, \mathbf{2 b}, \mathbf{3 b}$ and $\mathbf{1 b}$. Control experiments without $\mathbf{P}-\mathbf{1 b}$ were also analyzed, and no $\mathbf{P}-\mathbf{1} \mathbf{b}, \mathbf{2} \mathbf{b}, \mathbf{3} \mathbf{b}$ or $\mathbf{1 b}$ was detected in these samples (data not shown). As shown in Figure 5 , compounds $\mathbf{2} \mathbf{b}$ and $\mathbf{3 b}$ are produced in E. faecium within the first hour. The intracellular concentrations of $\mathbf{P}-\mathbf{1} \mathbf{b}$ and of $\mathbf{3} \mathbf{b}$ are higher than that of $\mathbf{2} \mathbf{b}$ for the entire experiment. This phenomenon is consistent with PanK being the rate-limiting enzyme in the bioactivation of $\mathbf{P}$-1 $\mathbf{b}$ to $\mathbf{3 b}$, as suggested by others for some microorganisms. ${ }^{[24],[25]}$ It is worth noting that even after $6 \mathrm{~h}$, no inhibitor $\mathbf{1 b}$ was detected (L.O.D = $0.05 \mathrm{pmol}$ ). Even though these studies were performed with E. faecium cells, the absence of detectable amounts of $\mathbf{1 b}$ is consistent with the results obtained with purified E. coli PanK, PPAT and DPCK, where P-1b was transformed into $10 \% \mathbf{1 b}+20 \% \mathbf{2 b}+70 \% \mathbf{3 b} \cdot{ }^{[15]}$ Nevertheless, because little to no $\mathbf{1 b}$ is detected, neither of these data sets can explain the time-kill results which suggest that $\mathbf{P}-\mathbf{1} \mathbf{b}$ has taken effect within the first hour, nor the potentiating effect of $\mathbf{P}$ 1a (which is not transformed to 1a either) on the antibacterial activity of ribostamycin (Figure 3A, right panel). 


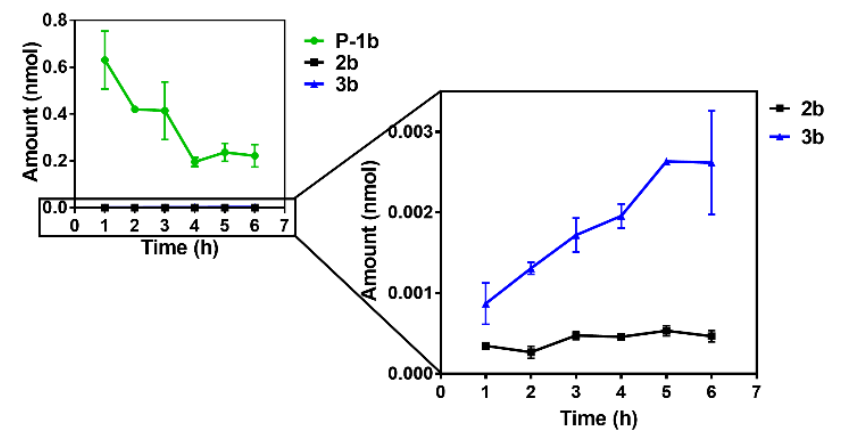

Figure 5. Transformation of $\mathbf{P}-\mathbf{1} \mathbf{b}$ in E. faecium measured by LCMS, with detection of $\mathbf{P}-\mathbf{1} \mathbf{b}, \mathbf{2} \mathbf{b}$ and $\mathbf{3} \mathbf{b}$ in cells. No $\mathbf{1 b}$ was detected (L.O.D $=0.05$ pmol).

Since $\mathbf{3 b}$ was found to rapidly accumulate during the first five hours, it was envisaged that the potentiating effect observed during the time-kill studies might be attributed in large part to $3 \mathbf{b}$. No $K_{i}$ values are reported for the inhibition of $A A C\left(6^{\prime}\right)$-li by $\mathbf{2 b}$ or $\mathbf{3 b}$, however, $K_{i}$ values are known for P-1a $(\geq 500 \mu \mathrm{M})$, the phosphorylated $\mathbf{2 a}(12 \mu \mathrm{M})$, and the CoA derivatives $\mathbf{1 a}$ $(0.076 \mu \mathrm{M})$ and $\mathbf{1 b}(0.043 \mu \mathrm{M}){ }^{[7]-[8],[15]}$ These numbers suggest that the AAC(6')-li inhibitory activity of $3 \mathbf{a}$ (which lacks only one phosphate group compared to 1a) might be somewhere in between those of $\mathbf{1 a}$ and $\mathbf{2 a}$, and considering that the $\mathrm{AAC}\left(6^{\prime}\right)$-inhibitory activities of $\mathbf{1} \mathbf{b}$ and $\mathbf{1 a}$ are very similar, we expect compound $\mathbf{3} \mathbf{b}$ to be a potent inhibitor of $E$. faecium AAC(6')-li.

\section{Inhibition of AAC(6')-li by $3 b$}

Pure $\mathbf{3 b}$ was prepared enzymatically from $\mathbf{P}-\mathbf{1 b}$ and ATP, using purified E. coli PanK and E. coli PPAT as the catalysts (Scheme 1). The resulting compound $\mathbf{3 b}$ was purified by HPLC before enzyme inhibition studies. The $K_{i}$ of $3 \mathbf{b}$ for $A A C\left(6^{\prime}\right)$-li was measured using the previously reported method. ${ }^{[7]-[8]}$ As expected, compound $3 \mathbf{b}$ is a competitive (vs AcCoA), tightbinding inhibitor of $A A C\left(6^{\prime}\right)$-li, with a $K_{i}$ of $0.12 \pm 0.04 \mu \mathrm{M}$. This is only $\sim 3$-fold higher than the $\mathrm{K}_{i}$ of $1 \mathrm{~b}(0.043 \pm 0.023 \square \mu \mathrm{M})^{[7]-}$ [8] and provides an explanation for the observed potentiating effect of $\mathbf{P}-\mathbf{1} \mathbf{b}$ in the absence of a significant amount of $\mathbf{1 b}$ being produced. This may also explain the potentiating effect of P-1a on the antibacterial activity of ribostamycin. Since 1a and $\mathbf{1 b}$ show similar inhibitory activity towards $A A C\left(6^{\prime}\right)$-li, like $\mathbf{3 b}, \mathbf{3 a}$ is likely a potent $A A C\left(6^{\prime}\right)$-li inhibitor. We therefore propose that the in cellulo bioactivation of $\mathbf{P}-\mathbf{1} \mathbf{b}$ leads to the formation of at least two AAC $\left(6^{\prime}\right)$-li inhibitors (2b and $\left.\mathbf{3 b}\right)$, and maybe a very small amount of $\mathbf{1} \mathbf{b}(<10 \%$ based on in vitro studies), with $\mathbf{3} \mathbf{b}$ contributing the most to the potentiation effect.<smiles>CC1CN(C(=O)NCCSCCNC(=O)CCNC(=O)C(C)(O)CO)[C@H](O)[C@@H](O)[C@H](N)O1</smiles>

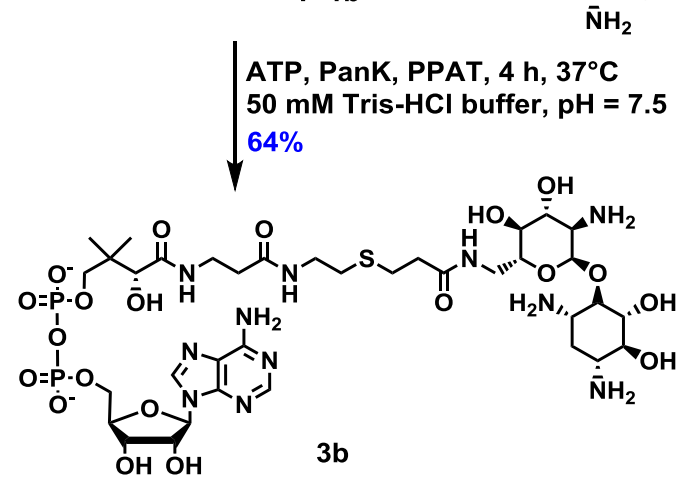

Scheme 1. Synthesis of compound $\mathbf{3 b}$. 


\section{Stability studies of $\mathbf{P}-\mathbf{1 b}$}

The stability of $\mathbf{P}-\mathbf{1 b}$ was next investigated. The half-life of $\mathbf{P}-\mathbf{1 b}$ in human serum is $7.2 \pm 0.6 \mathrm{~h}$ (Figure $6 \mathrm{~A}$ ), which is significantly longer than its onset of action. Indeed our results show that $\mathbf{P}-\mathbf{1 b}$ takes effect within the first hour, its effect lasts at least $16 \mathrm{~h}$ based on MIC determinations, and the in cellulo bioactivation studies reveal the presence of $\mathrm{AAC}\left(6^{\prime}\right)$-li inhibitor $\mathbf{3 b}$ in cells within the first hour.

The stability of $\mathbf{P}-\mathbf{1} \mathbf{b}$ towards the action of P450 enzymes was also evaluated. We found that the metabolism of $\mathbf{P}-\mathbf{1} \mathbf{b}$ by rat liver microsomes is much slower than that of testosterone (Figure $6 \mathrm{~B}$ ). The relatively long half-life of $\mathbf{P}-\mathbf{1} \mathbf{b}$ in blood and its slow metabolism by P450 enzymes are both desirable traits for drug candidates.

A. Stability study of $\mathbf{P}-\mathbf{1} \mathbf{b}$ in human serum

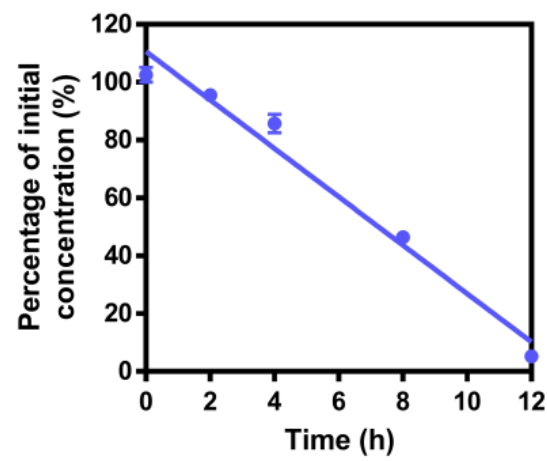

B. Stability study towards rat liver microsomes

\begin{tabular}{ccc}
\hline \multirow{2}{*}{ Time $(\min )$} & \multicolumn{2}{c}{ Turnover $(\mathrm{pmol} / \mathrm{min} / \mathrm{mg}$ protein) } \\
\cline { 2 - 3 } 30 & $\mathbf{P}-1 \mathbf{b}$ & Testosterone \\
\hline \multirow{2}{*}{$5.4 \pm 0.2$} & $128.7 \pm 0.7$
\end{tabular}

Figure 6. Stability studies of P-1b, A) in human serum, and B) towards P450 enzymes (rat liver microsomes).

The aminoglycoside potentiating effect of $\mathrm{P}-1 \mathrm{~b}$ against other bacterial strains

Compound P-1b effectively potentiates the antibacterial activity of aminoglycosides towards the intrinsically resistant Grampositive bacterium $E$. faecium. Its activity in Gram-negative bacteria was investigated next. An aminoglycoside-resistant $E$. coli strain was generated by transformation of competent $E$. coli BL21 cells with the plasmid $\mathrm{pET} 22 \mathrm{~b}(+) / \mathrm{AAC}\left(6^{\prime}\right)-\mathrm{li}$. As expected, the resulting strain (abbreviated BL21-AAC(6')-li) is more resistant towards ribostamycin than the original strain (abbreviated BL21; Figure 7A). Interestingly, in the presence of $\mathbf{P}-\mathbf{1 b}$, the MIC of ribostamycin towards BL21-AAC(6')-li decreased considerably. This result demonstrates that $\mathbf{P}-\mathbf{1 b}$ can enter Gram-negative bacterial cells and potentiate the activity of aminoglycosides.

Since P-1b itself does not inhibit AAC(6')-li, it can only take effect after being transformed by the CoA biosynthetic enzymes in bacteria. To confirm that the CoA biosynthetic enzymes of $E$. coli are involved in the bioactivation of $\mathbf{P}-\mathbf{1 b}$, as is the case in vitro and in $E$. faecium, the aminoglycoside-potentiating activity of $\mathbf{P}-\mathbf{1} \mathbf{b}$ was studied towards $\mathrm{BL} 21-\mathrm{AAC}\left(6^{\prime}\right)$-li in the presence of excess pantothenate. During bioactivation, P-1b must compete with pantothenate for the CoA biosynthetic enzymes. It was therefore hypothesized that excess pantothenate in the growth medium of BL21-AAC(6')-li may outcompete $\mathbf{P}-\mathbf{1 b}$, thus decreasing its bioactivation by the CoA biosynthetic enzymes and reducing the aminoglycoside potentiation observed. As shown in Figure 7B, the MIC of the ribostamycin-P-1b combination for BL21-AAC $\left(6^{\prime}\right)$-li increased when the minimal growth medium (no pantothenate) was supplemented with $0.1 \mathrm{mM}$ pantothenate. This supports our hypothesis that, as in E. faecium, the activity of $\mathbf{P}-\mathbf{1 b}$ in $E$. coli requires an input from the CoA biosynthetic enzymes. 

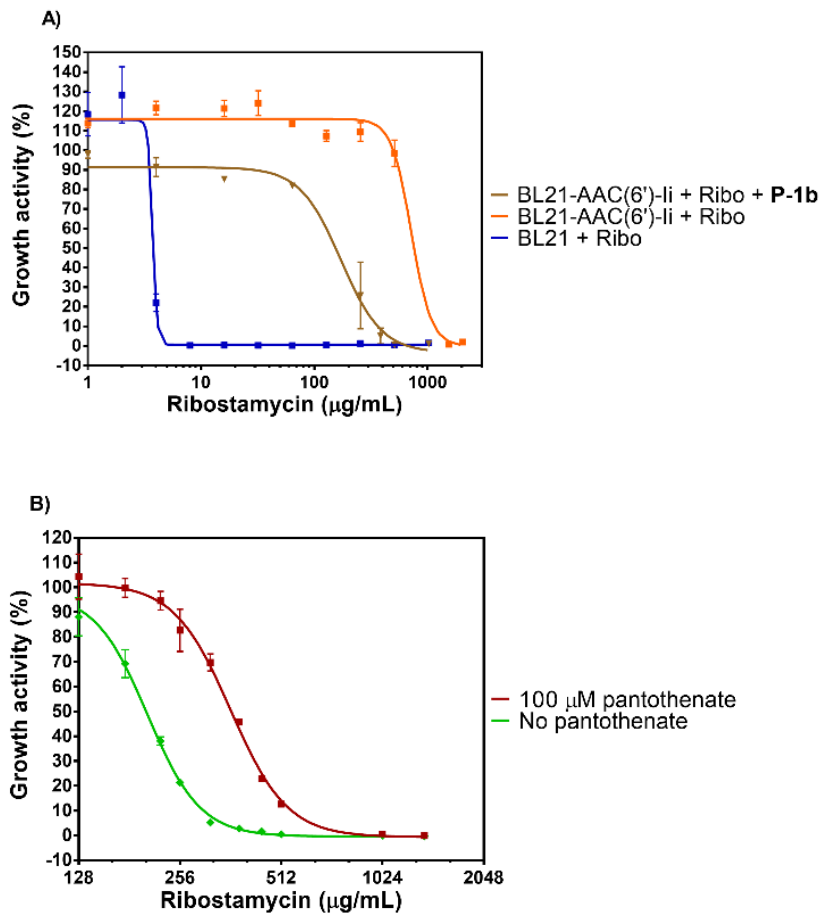

Figure 7. Potentiating effect of $\mathbf{P}-\mathbf{1 b}(512 \mu \mathrm{g} / \mathrm{mL})$ on the antibacterial activity of ribostamycin towards different $E$. coli strains, A) in minimal medium (M9 $+0.2 \%$ glycerol) and $\mathrm{B}$ ) in minimal medium (M9 + 0.2\% glycerol) with or without $100 \mu \mathrm{M}$ pantothenate added.

We next turned to vancomycin-resistant Enterococci (VRE) because of its rapidly increasing prevalence (as high as $44 \%$ in some countries) and the difficulty to treat VRE infections. Since the mechanisms evolved by bacteria to resist aminoglycosides are very different from those evolved to resist vancomycin (drug modification versus alteration to the structure of peptidoglycans), we expected $\mathbf{P}-\mathbf{1 b}$ to also resensitize VRE to aminoglycosides. Our results show that compound $\mathbf{P}-\mathbf{1 b}(16 \mu \mathrm{g} / \mathrm{mL})$ can greatly decrease the MIC of different aminoglycosides towards VRE 2010A and VRE BAA2316, two clinical strains (Table 1).

Table 1. Potentiating effect of compound P-1b $(16 \mu \mathrm{g} / \mathrm{mL})$ on the antibacterial activity of different aminoglycosides against two clinical VRE strains.

\begin{tabular}{lcccc}
\hline \multirow{2}{*}{ VRE strain } & Compound & \multicolumn{3}{c}{ MIC $(\mu \mathrm{g} / \mathrm{mL})$} \\
\cline { 3 - 5 } & & Tobramycin & Kanamycin & Ribostamycin \\
\hline $2010 A$ & No P-1b & 128 & \\
2010A & P-1b $(16 \mu \mathrm{g} / \mathrm{mL})$ & 32 & 256 & 512 \\
BAA2316 & No P-1b & 128 & & 64 \\
BAA2316 & $\mathbf{P}-\mathbf{1 b}(16 \mu \mathrm{g} / \mathrm{mL})$ & 32 & 64 & \\
\hline
\end{tabular}

\section{Cell cytotoxicity studies}

The cytotoxicity of P-1b was investigated using HeLa cells. As shown in Figure 8, even at a concentration of $1024 \mu \mathrm{g} / \mathrm{mL}, \mathbf{P}$ 1b had little effect, if any, on the growth of HeLa cells. 


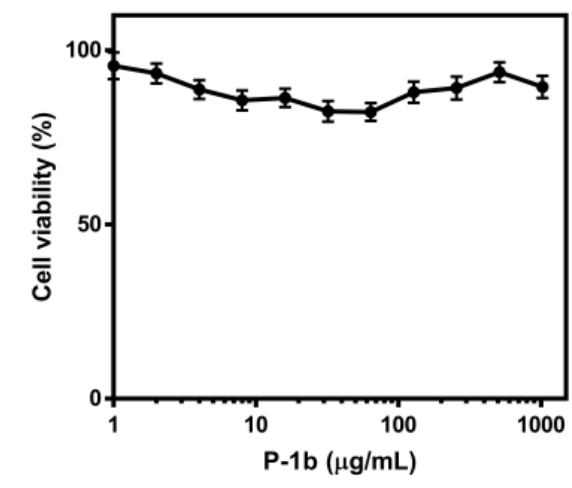

Figure 8. Effect of P-1b on the growth of HeLa cells.

\section{Conclusions}

Our group has demonstrated the use of CoA biosynthetic enzymes in prodrug activation. ${ }^{[15],[26]}$ Moreover, many pantothenate derivatives are known to act as antimetabolites and be transformed by the CoA biosynthetic enzymes in bacteria. ${ }^{[24],[25]}$ While it has been suggested in these studies that the active metabolite is the corresponding CoA derivative, the results presented here show that, at least for $\mathbf{P}-\mathbf{1} \mathbf{b}$, an earlier intermediate (3b here) is the most important active molecule. Moreover, the cellular studies reported herein with $\mathbf{P}-\mathbf{1 b}$ reveal that bioactivation and AAC(6')-li inhibition occur within one hour.

Based on the absence of cell cytotoxicity observed at high concentrations of $\mathbf{P}-\mathbf{1} \mathbf{b}$, its reasonable blood stability, slow metabolism, and ability to penetrate both Gram-positive and Gram-negative bacteria, we believe that this compound is a good starting point for the development of drugs to inhibit aminoglycoside resistance. Interestingly, because the unnatural part of our molecules (relative to the corresponding natural substrates) is expected to lie outside of PanK, PPAT and DPCK, ${ }^{[16]-[18]}$ we believe that the emergence of resistance may be slow.

Antibacterial resistance is growing to be a severe health issue around the world. ${ }^{[27]}$ Inhibiting resistance-causing enzymes is a validated approach for the design of new combination drugs to treat resistant infections. ${ }^{[28]}$ While several inhibitors of $\beta$ lactam resistance are used in the clinic, this is not the case for aminoglycoside resistance inhibitors. Our results suggest that compounds $\mathbf{P}-\mathbf{1} \mathbf{b}-\mathbf{d}$ are promising hits for the design of such drugs. In particular, $\mathbf{P}-\mathbf{1} \mathbf{b}-\mathbf{d}$ significantly reduce the MIC of different aminoglycosides towards E. faecium, an important nosocomial pathogen. Because enterococcal infections are intrinsically resistant to aminoglycosides, $\beta$-lactams, macrolides and clindamycin, their treatment typically requires drug combinations. The treatment of enterococcal infections is further complicated by the rapid spread of plasmids encoding additional resistance-causing genes. ${ }^{[29]}$ As many as $1 / 3$ of all enterococcal infections in intensive care units are also vancomycin-resistant. Our results suggest that $\mathbf{P}-\mathbf{1} \mathbf{b}$ has potential for the treatment of VRE infections.

\section{Experimental Section}

Experimental details were described in the supporting information.

\section{Acknowledgements}

This work was financially supported by a grant from the Canadian Institute of Health Research (to K.A.).

We are grateful to Dr. Gerry Wright for providing the pET22b(+)/AAC(6')-li plasmid, Dr. Fabien N. Hammerer for providing the purified PPAT and DPCK enzymes, Eric Ma for providing the purified PanK enzymes, and Dr. Thibodeaux for providing the competent BL21 cells. The China Scholarship Council is thanked for financial support to J.G.

Keywords: aminoglycoside $\cdot$ resistance inhibitor $•$ coenzyme A $•$ Enterococcus faecium $•$ vancomycin-resistant Enterococci

[1] B. Becker, M. A. Cooper, ACS Chem. Biol. 2013, 8, 105-115. 
[2] Y. Takahashi, M. Igarashi, J. Antibiot. (Tokyo) 2017.

[3] S. G. Zarate, M. L. De la Cruz Claure, R. Benito-Arenas, J. Revuelta, A. G. Santana, A. Bastida, Molecules 2018, 23 , pii: E284.

[4] M. S. Ramirez, M. E. Tolmasky, Drug Resist. Updat. 2010, 13, 151-171.

[5] K. J. Labby, S. Garneau-Tsodikova, Future Med. Chem. 2013, 5, 1285-1309.

[6] J. W. Chow, Clin. Infect. Dis. 2000, 31, 586-589.

[7] F. Gao, X. Yan, O. M. Baettig, A. M. Berghuis, K. Auclair, Angew. Chem. Int. Ed. Engl. 2005, 44, 6859-6862.

[8] F. Gao, X. Yan, T. Shakya, O. M. Baettig, S. Ait-Mohand-Brunet, A. M. Berghuis, G. D. Wright, K. Auclair, J. Med. Chem. 2006, 49, 5273-5281.

[9] X. Yan, F. Gao, S. Yotphan, P. Bakirtzian, K. Auclair, Bioorg. Med. Chem. 2007, 15, 2944-2951.

[10] M. L. Magalhaes, M. W. Vetting, F. Gao, L. Freiburger, K. Auclair, J. S. Blanchard, Biochemistry 2008, 47, 579-584.

[11] F. Gao, X. Yan, O. Zahr, A. Larsen, K. Vong, K. Auclair, Bioorg. Med. Chem. Lett. 2008, 18, 5518-5522.

[12] F. Gao, X. Yan, K. Auclair, Chemistry 2009, 15, 2064-2070.

[13] X. Yan, T. O. Akinnusi, A. T. Larsen, K. Auclair, Org. Biomol. Chem. 2011, 9, 1538-1546.

[14] J. Szychowski, J. Kondo, O. Zahr, K. Auclair, E. Westhof, S. Hanessian, J. W. Keillor, ChemMedChem 2011, 6, 1961-1966.

[15] K. Vong, I. S. Tam, X. Yan, K. Auclair, ACS Chem. Biol. 2012, 7, 470-475.

[16] R. A. Ivey, Y. M. Zhang, K. G. Virga, K. Hevener, R. E. Lee, C. O. Rock, S. Jackowski, H. W. Park, J. Biol. Chem. 2004, 279, 35622-35629.

[17] T. Izard, J. Mol. Biol. 2002, 315, 487-495.

[18] J. Badger, J. M. Sauder, J. M. Adams, S. Antonysamy, K. Bain, M. G. Bergseid, S. G. Buchanan, M. D. Buchanan, Y. Batiyenko, J. A. Christopher, S. Emtage, A. Eroshkina, I. Feil, E. B. Furlong, K. S. Gajiwala, X. Gao, D. He, J. Hendle, A. Huber, K. Hoda, P. Kearins, C. Kissinger, B. Laubert, H. A. Lewis, J. Lin, K. Loomis, D. Lorimer, G. Louie, M. Maletic, C. D. Marsh, I. Miller, J. Molinari, H. J. Muller-Dieckmann, J. M. Newman, B. W. Noland, B. Pagarigan, F. Park, T. S. Peat, K. W. Post, S. Radojicic, A. Ramos, R. Romero, M. E. Rutter, W. E. Sanderson, K. D. Schwinn, J. Tresser, J. Winhoven, T. A. Wright, L. Wu, J. Xu, T. J. Harris, Proteins 2005, 60, 787-796.

[19] A. D. M. Kashuba, J. S. Bertino, A. N. Nafziger, Antimicrob. Agents Chemother. 1998, 42, 1842-1844.

[20] A. Prayle, A. Watson, H. Fortnum, A. Smyth, Thorax 2010, 65, 654-658.

[21] S. Pagkalis, E. Mantadakis, M. N. Mavros, C. Ammari, M. E. Falagas, Drugs 2011, 71, 2277-2294.

[22] G. A. Pankey, L. D. Sabath, Clin. Infect. Dis. 2004, 38, 864-870.

[23] M. K. Lacy, D. P. Nicolau, C. H. Nightingale, R. Quintiliani, Clin. Infect. Dis. 1998, 27, 23-27.

[24] C. Spry, K. Kirk, K. J. Saliba, FEMS Microbiol. Rev. 2008, 32, 56-106.

[25] W. J. Moolman, M. de Villiers, E. Strauss, Biochem. Soc. Trans. 2014, 42, 1080-1086.

[26] F. Hammerer, J. H. Chang, D. Duncan, A. Castaneda Ruiz, K. Auclair, ChemBioChem 2016, 17, 1513-1517.

[27] C. L. Ventola, P T 2015, 40, 277-283.

[28] C. Gonzalez-Bello, Bioorg. Med. Chem. Lett. 2017, 27, 4221-4228.

[29] S. L. Fraser, C. J. Donskey, R. A. Salata, Enterococcal infections. Medscape, Drugs \& Diseases 2017. 